\title{
Modelling of the Thermal Field in Dissimilar Alloy Ultrasonic Welding
}

\author{
P. Jedrasiak, H.R. Shercliff, Y.C. Chen, L. Wang, P. Prangnell, and J. Robson
}

Copyright 2014 ASM International. This paper was published in Journal of Materials Engineering and Performance Volume 24, Issue 2, pp 799-807 and is made available as an electronic reprint with the permission of ASM International. One print or electronic copy may be made for personal use only. Systematic or multiple reproduction, distribution to multiple locations via electronic or other means, duplications of any material in this paper for a fee or for commercial purposes, or modification of the content of this paper are prohibited. 


\title{
Modeling of the Thermal Field in Dissimilar Alloy Ultrasonic Welding
}

\author{
P. Jedrasiak, H.R. Shercliff, Y.C. Chen, L. Wang, P. Prangnell, and J. Robson
}

\author{
(Submitted September 8, 2014; in revised form November 19, 2014; published online December 10, 2014)
}

\begin{abstract}
This paper describes a finite element model for predicting the temperature field in high power ultrasonic welding aluminum AA6111 to two dissimilar alloys, magnesium AZ31, and low carbon steel DC04. Experimental thermocouple and other evidence are used to infer the magnitude and distribution of the heat input to the workpiece, as a function of time, for each of the material combinations welded. The resulting temperature histories are used to predict the growth of intermetallic phases at the interface in Al-Mg welds. The microstructural model successfully predicts the thickness of the intermetallic layer, but the sensitivity of the results to temperature is demonstrated.
\end{abstract}

Keywords aluminum, finite element, joining, magnesium, modeling and simulation, ultrasonic, welding

\section{Introduction}

The increased use of light alloys to improve energy efficiency in automotive and other transport applications bring with it the need to develop joining technologies for aluminum, magnesium, and low carbon steels, including dissimilar joints between them. Traditional fusion processes such as resistance spot welding (RSW), arc methods, and laser welding are common for joining steels (Ref 1,2). RSW of aluminum and magnesium alloys is problematic, because of their high melting, resistive oxide layers, causing a reduction in weld quality (Ref 3 ). The degradation of mechanical properties can be reduced or avoided by solid-state joining methods, for instance, selfpiercing rivets, or friction methods. But if the temperature is raised during joining, many issues remain for design with dissimilar materials. Thermal property mismatch may exacerbate stress build-up, leading to cracking and distortion of the assembly (Ref 4, 5). And even though solidification microstructures are avoided, there is still the risk of formation of weak intermetallic compounds at the interface (Ref 6). However, friction welding methods limit the heat input and process time, so the thickness of intermetallic can be minimized (Ref 7). Also, the high strain rates promote dynamically recrystallized microstructures with properties that are often comparable, or even superior, to those of the base metal (Ref 8, 9). Finally, compared to fusion methods, friction welding methods are usually fast, easy to automate, and more energy and cost efficient (Ref 10).

P. Jedrasiak and H.R. Shercliff, Engineering Department, Cambridge University, Trumpington St, Cambridge CB2 1PZ, UK; and Y.C. Chen, L. Wang, P. Prangnell, and J. Robson, Materials Science Centre, Manchester University, Grosvenor St, Manchester M1 7HS, UK. Contact e-mail: hrs@eng.cam.ac.uk.

Ultrasonic welding (USW) of metals may be classified as a friction welding technique, and brings with it the same advantages (Ref 11-17). It has recently become applicable for thicker parts, thanks to the availability of high power USW systems (Ref 18). High power USW is suitable for bonding similar and dissimilar non-ferrous soft metals and their alloys (aluminum, magnesium, copper, brass, gold, and silver) (Ref 19-21). Figure 1 illustrates the principle, for ultrasonic spot welding (Ref 22): high frequency vibrations are applied parallel to the weld interface for welding times of order one second or less under a moderate static clamping pressure, limiting the energy input, and producing a solid-state joint by plastic deformation (Ref 19, 23-25).

A limited number of attempts have been made to model high power ultrasonic welding of metals. Siddiq and Ghassemieh modeled seam welding of thin aluminum alloy foil with a rolling sonotrode (Ref 26, 27). The model used an experimentally derived friction coefficient, and plastic deformation including thermal and ultrasonic softening effects, though without strain-rate dependence in the yield stress, despite the high strain rates experienced in USW. The model complexity limited the analysis to material adjacent to the tool-workpiece interface for very short weld durations. Elangovan et al. (Ref $22,25)$ created a finite element (FE) model of ultrasonic spot welding, predicting the temperature and stress distribution in aluminum joints. The accuracy of this model was limited by the material thermal properties used being independent of temperature, and the assumption of a constant heat input, estimated from a constant coefficient of friction and single value of yield strength. Similar limitations apply to the FE model by Kim et al. (Ref 28), who used the Johnson-Cook material deformation model, which is not generally well suited to the hot deformation regime in friction joining processes. The authors also noted that their explicit, coupled analysis required very long run-times. FE models have also been developed for ultrasonic consolidation, which is essentially the same process, assuming interface friction as the only heat source, without plastic dissipation (Ref 29-31). This model simulates every cycle within the process (around 3000), but no comparison was made between predicted and experimental temperature histories predictions. 


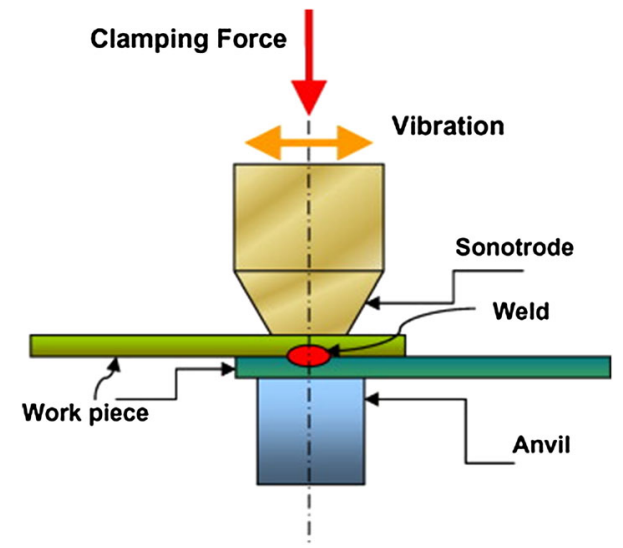

Fig. 1 Schematic of the principle of ultrasonic welding (Ref 22)

It is clear that USW modeling is limited by the assumptions made about frictional and plastic heat generation, and that current models can be computationally intensive in spite of the very short welding times. And models have not yet considered USW for dissimilar metal combinations. Fully describing the process is challenging due to its complexity and high frequency (Ref 13). The joining mechanism evolves from friction to seizure and bulk plastic deformation, governed by break-up of contaminant films at the interface and material heating and softening; these in turn depend on the clamping force, oscillation amplitude, weld time, and the materials being welded.

In the current project, computationally efficient solutions are being sought for a range of friction-based processes (Ref 32). The key concept is the use of a sequentially coupled deformation model and a thermal model: the first predicts the heat generation over a short time interval, directly from the constitutive behavior of the material, while the thermal model updates the thermal field over a much longer time interval, before the computational cycle repeats. This paper presents the development of a reliable thermal model from which an estimate of the heat generation history can be inferred. This is a necessary first step when direct measurement of the power input to the workpiece is difficult, as is the case for ultrasonic welding. A secondary objective is the development of a simple thermal model to enable predicted thermal histories to be coupled to microstructural models, for example, for intermetallic growth at the interface $(\operatorname{Ref} 33,34)$.

\section{Experimental Input to the Model}

The experimental work was conducted by the project partners at Manchester Materials Science Centre, and has been reported in detail elsewhere (Ref 18, 23, 33-38). The relevant parts of the work, which inform and validate the FE model in this paper, are summarized here.

A Sonobond Ultrasonic MH2016 dual-reed machine was used for welding, at a constant frequency of $20.5 \mathrm{kHz}$. The peak-to-peak amplitude of the sinusoidal oscillation was of the order of $5 \mu \mathrm{m}$, measured by high-speed camera (Ref 35, 39). This is much smaller than the dimensions of contact area, which may, therefore, be assumed to be constant and stationary. The energy delivered to the sample depends on the machine settings for power input and impedance. The latter was optimized for every material combination, in order to maximize

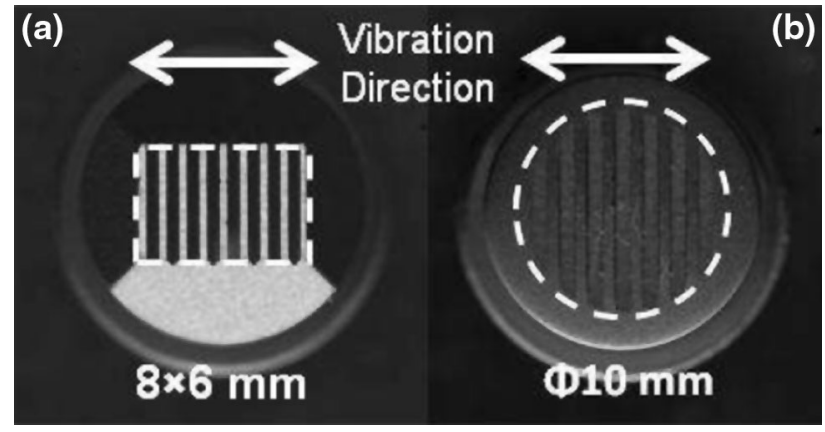

Fig. 2 Sonotrode welding tips for (a) aluminum or magnesium and (b) steel (Ref 35)

energy delivery (Ref 39). The resulting nominal rate of energy delivery was approximately $1.5 \mathrm{~kW}$ for all three material combinations, while the clamping force was set to constant values of $1.9 \mathrm{kN}$ for $\mathrm{Al}-\mathrm{Mg}$ and $\mathrm{Al}-\mathrm{Al}$ welds, and $1.4 \mathrm{kN}$ for Al-steel welds (Ref 35, 39).

A standard sonotrode welding tip was used for the aluminum and magnesium sheets, but for the steel sheet, a dome-shaped tip with shallow knurling was necessary to avoid surface damage. The sonotrode tips are shown in Fig. 2. Welding times for thermal analysis were: for Al-Al, $0.5 \mathrm{sec}$; for Al-steel, 0.25, 0.75, $1.5,2.25$, and $3 \mathrm{sec}$; and for Al-Mg, 0.3, 0.5, 0.7, 0.9, and $1.3 \mathrm{sec}$. During welding, the tools are under a constant static load, and first indent the surface until the grooves are full, which does not require expulsion of any material from the weld zone. Subsequent indentation of the sheets is more strongly resisted, as metal must flow out of the region between the tools. Cross-sections in Al-Al welds after different weld times are shown in Fig. 3, from which it was inferred that the grooves were filled within $0.3 \mathrm{sec}$, and significant thinning only occurred for weld times well beyond the maximum considered for thermal analysis (Ref 40). Hence for each of the material combinations, fixed tool positions were assigned for all the welds, regardless of the weld time. The fixed positions were defined by depths $h_{1}$ and $h_{2}$ (Fig. 3d), and were the average tool positions for the longest weld made in each material combination ( $0.5 \mathrm{sec}$ for Al-Al, $1.3 \mathrm{sec}$ for $\mathrm{Mg}-\mathrm{Al}$, and $3 \mathrm{sec}$ for Al-steel), based on micrographs such as Fig. 3a-c.

The welds consisted of one sheet of aluminum alloy 6111-T4, with the second sheet being 6111-T4, or low carbon steel DC04, or magnesium alloy AZ31. The nominal compositions are shown in Table 1 . Test coupons were $100 \times 25 \mathrm{~mm}$, in a lap configuration with $25 \mathrm{~mm}$ overlap. Sheet thicknesses were $0.93 \mathrm{~mm}$ (6111 aluminum), $0.97 \mathrm{~mm}$ in DC04 steel, and $1.05 \mathrm{~mm}$ in AZ31 magnesium. The steel had its thin anti-corrosion layer removed with fine sand paper prior to welding. Temperature histories were recorded with $0.5 \mathrm{~mm} k$-type thermocouples positioned at the weld center, touching the weld interface. In dissimilar welds, thermocouples were also located at the weld edges, and for the Al-Mg weld, a further thermocouple was embedded in the tool, $0.5 \mathrm{~mm}$ from the tip surface.

Many welds were tested to failure, and investigated by optical and electron microscopy, by the project partners in Manchester. Particular results relevant to the modeling work presented here are as follows. For short duration Al-Al welds (less than about $0.2 \mathrm{sec}$ ), progressive growth in asperity contact was revealed, though the welds still failed at the interface (Ref 18). This indicates an initial phase of frictional rubbing at the interface, heating the asperity contacts which grow until seizure, at which point the tool displacement is accommodated entirely by plastic 

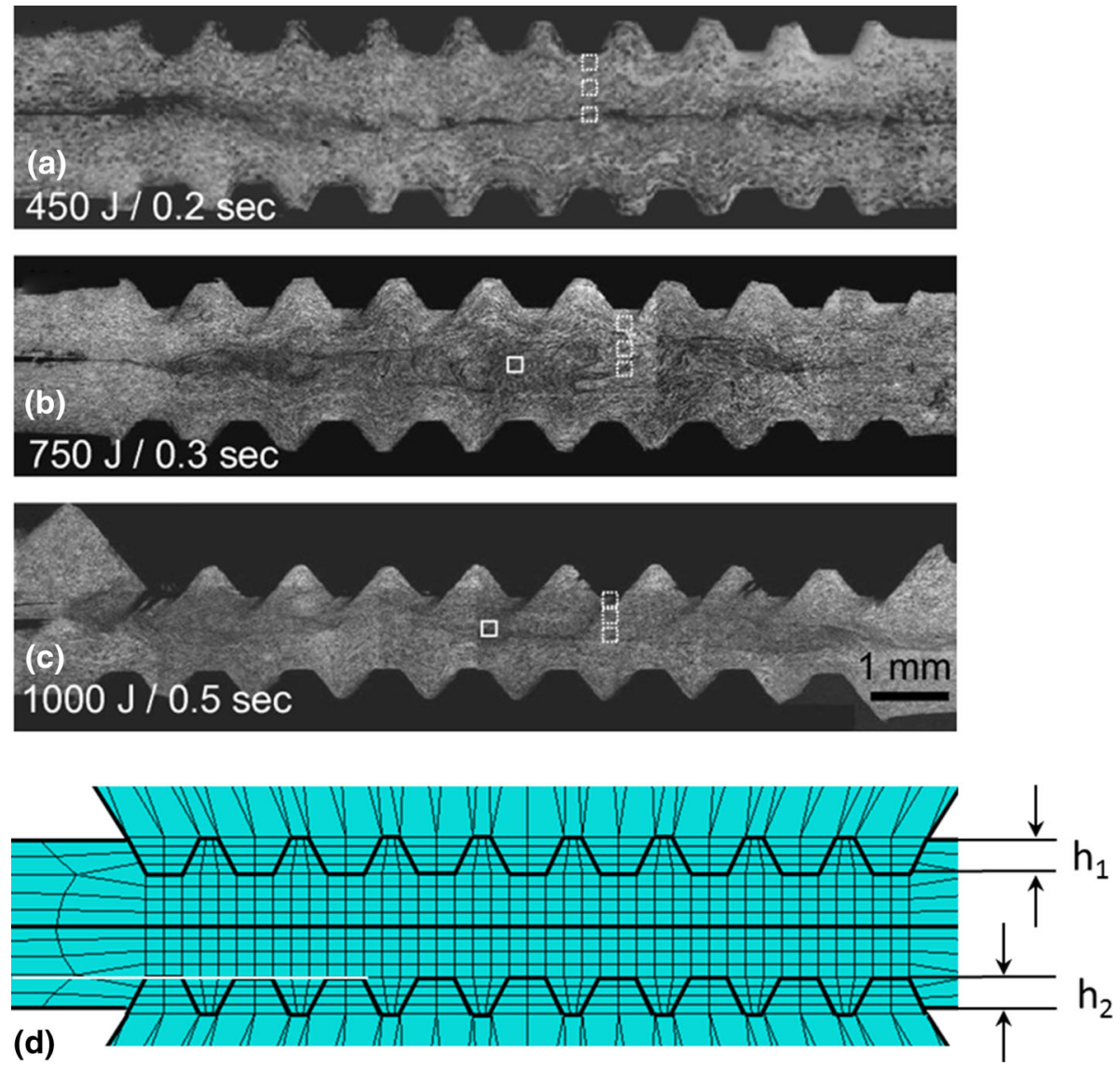

Fig. 3 (a-c) Cross-sections through Al-Al welds after various times (after Ref 36), and (d) detail of the FE model of the weld region, defining the tool indentation depths

Table 1 Nominal compositions of the alloys (wt.\%)

\begin{tabular}{llllllllllllll}
\hline & Al & \multicolumn{1}{c}{$\mathbf{C}$} & $\mathbf{C u}$ & $\mathbf{C r}$ & $\mathbf{F e}$ & $\mathbf{M g}$ & $\mathbf{M n}$ & $\mathbf{M o}$ & $\mathbf{S i}$ & $\mathbf{T i}$ & $\mathbf{Z n}$ & $\mathbf{P}$ & $\mathbf{S}$ \\
\hline Al 6111 & Bal. & $<0.01$ & 0.70 & $<0.01$ & 0.25 & 0.75 & 0.3 & $<0.01$ & 0.85 & 0.04 & $<0.01$ & $\ldots$ & $\ldots$ \\
Mg AZ31 & 3.0 & $\ldots$ & $<0.01$ & $\ldots$ & $<0.03$ & Bal. & 0.5 & $\ldots$ & 0.1 & $\ldots$ & 1.0 & $\ldots$ & $\ldots$ \\
DC04 steel & $\ldots$ & 0.08 & $\ldots$ & $\ldots$ & Bal. & $\ldots$ & 0.4 & $\ldots$ & $\ldots$ & $\ldots$ & $\ldots$ & 0.03 & 0.03 \\
\hline
\end{tabular}

deformation. Plasticity remains concentrated toward the interface, since the temperature gradient through-thickness will lead to greatest softening near the interface. The optimum joint strength is associated with the development of a metal-metal bond over the full weld area, but without excessive thinning. Heat generation is, therefore, assumed to be concentrated at the interface throughout welding, and the variation of power input is expected to initially rise (as the contact area increases until seizure) and then to decrease, once full contact is established, due to thermal softening of the material. The thermocouple measurements indicated that successful bonding was associated with a peak interface temperature in the range of $400-420{ }^{\circ} \mathrm{C}$.

Scanning electron microscopy studies of the joint interface in dissimilar alloy welds revealed intermetallic reactions taking place (Ref 23, 33, 34, 39). For Al-Mg, the growth of the intermetallic layer was as follows: (a) isolated islands nucleate at the interface, elongated along the oscillation direction; (b) these islands spread laterally until they coalesce into a continuous layer; (c) the layer thickens reasonably uniformly with prolonged welding time; and (d) break-up of the intermetallic when the interface temperature reached the melting (eutectic) temperature. For very short welding times $(<0.5 \mathrm{sec})$, only one intermetallic phase $\left(\mathrm{Al}_{12} \mathrm{Mg}_{17}\right)$ is observed. A second phase $\mathrm{Al}_{3} \mathrm{Mg}_{2}$ forms rapidly at longer times and both compounds grow simultaneously- $\mathrm{Al}_{3} \mathrm{Mg}_{2}$ on the aluminum side, and $\mathrm{Al}_{12} \mathrm{Mg}_{17}$ on the magnesium side. The $\mathrm{Al}_{3} \mathrm{Mg}_{2}$ phase grows faster than the $\mathrm{Al}_{12} \mathrm{Mg}_{17}$ phase, and the former ends up dominating the overall layer thickness. The kinetics of the layer thickening process were investigated further by isothermal post-weld heat treatments, to grow thicker layers and improve calibration of the microstructural evolution model (see "Prediction of Intermetallic Growth at Interface in Al-Mg Welds" section, below).

\section{Thermal FE Modeling of Ultrasonic Welding}

\subsection{Model Development}

The weld geometry is symmetrical about a longitudinal vertical plane, so only half of the weld needs to be modeled. 
Figure 4 shows the geometry and mesh of the three-dimensional FE model. The insets to the figure show details of partial cross-sections of the weld region, showing the profiling and dimensions of the tools.

The sheet thicknesses were adjusted according to the material combination in the weld. Due to the short process times and the relatively low thermal conductivity of the tool steel used for the sonotrodes, only the ends of the sonotrode reed assembly were included. The mesh was graded in the tools, with the choice of the finest mesh size in the weld region being guided by previous work on friction stir spot welding (FSSW) of the same sheet thicknesses, with a similar tool footprint (Ref 41). Four materials were used in the model: 6111 aluminum, AZ31 magnesium, and DC04 steel sheet materials, as well as tool steel for the sonotrodes. The material models included temperature-dependent specific heat, thermal conductivity, and density (Ref 42-46).

For computational efficiency, the surfaces in contact with the air were treated as insulated, due to the low heat transfer coefficient to air, the short cycle time, and the relative remoteness of these surfaces to the thin weld region. The metal-to-metal contact between the workpieces is strongly influenced by the clamping pressure between the sonotrodes. Outside the weld zone, the workpieces are not pressed together, and often separate slightly as the weld is produced. Hence this part of the overlap was also considered to have an insulated thermal boundary. Over the weld area, however, the high pressure and surface sliding give intimate metal-metal contact, so this was modeled with a high contact conductance of $10^{6} \mathrm{Wm}^{-1} \mathrm{~K}^{-1}$. Finally, the contact between the workpieces and the moving tools will also be an intimate contact, again modeled assuming a high contact conductance of $10^{6} \mathrm{Wm}^{-1} \mathrm{~K}^{-1}$. The initial growth in the contact area was initially investigated by ramping up the contact conductance, but this was found to have a negligible effect, since full contact is established after a short period as the temperature rises at the tool-workpiece interface.

Heat generation was modeled as a uniform surface heat flux at the weld interface, varying in intensity with time. In the initial sliding frictional contact, it is assumed that a uniform pressure applies over the contact area. Cycles of remote oscillation will then induce alternating stick-slip behavior at the interface - sliding will cease at the maximum displacement in each direction, and will recommence when the interfacial stress has reversed in direction and reached the condition for frictional sliding. The limiting shear stress is expected to scale with the (uniform) pressure, suggesting that the spatial distribution of heating rate will be uniform. Heating is intermittent, due to the stick-slip behavior, but at the high process frequency, it may be applied continuously, representing an average over one cycle. As full contact is made, the same oscillating displacement is accommodated by plastic deformation, and the heat flux will depend in a complex way on the evolving temperature field and the constitutive response of the alloys as a function of temperature and strain rate. In the first instance, the heat flux is assumed to remain uniform over the contact area-investigation of this assumption is one aspect of modeling the fully coupled problem, which will be the subject of a subsequent paper. The heat flux was also applied only at the interface, though in practice it must spread into the bulk. This assumption follows previous research on FSSW of thin aluminum and steel sheets, which showed that, for thin deforming layers, the distribution of heat input between the weld interface and the bulk had little influence on the temperature distribution at the interface (Ref 41). Note also that the intermetallic layer that forms at the interface is not included in the thermal model. Although its thermal properties will differ from those of the workpiece materials, the thickness of the layer is very small and it only forms in the later stages of welding, so its influence on heat flow is negligible.

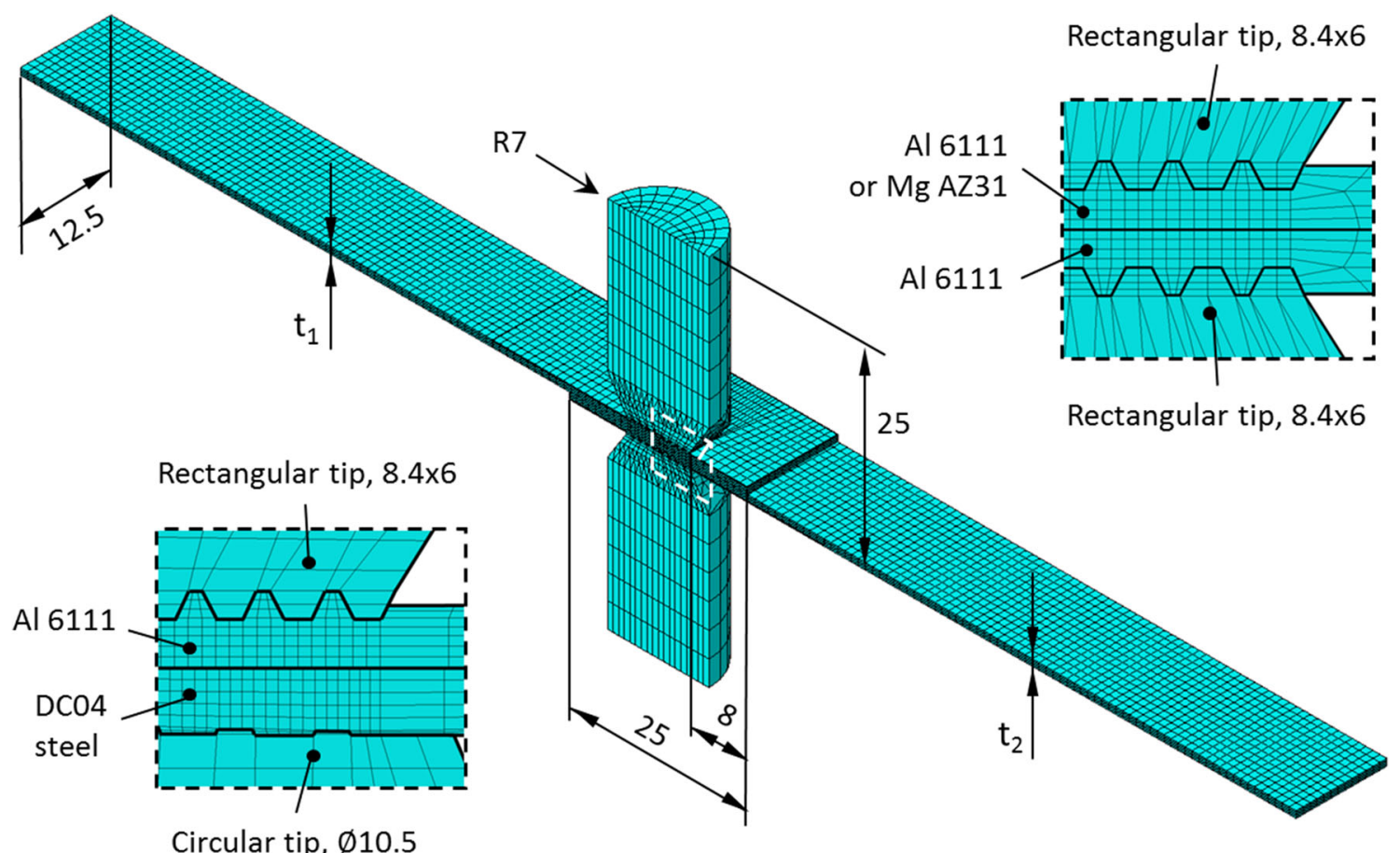

Fig. 4 Thermal finite element model: geometry and mesh (dimensions in $\mathrm{mm}$ ); inset: details of part of weld zone (white dashed area in main figure) 


\subsection{Model Calibration}

No direct measurements of power input are available for ultrasonic metal welding with standard machinery-quoted weld energies are simply the nominal machine power $\times$ weld time. Other friction welding processes do sometimes provide more insight into power input, for example, in friction stir processes, a nominal power is torque $\times$ rotation speed. But even then, this is not the power delivered at the workpiece, due to machine losses. It was, therefore, necessary for the power input to be reverse engineered as a function of time using selected reference welds, giving a semi-empirical process model. Full predictive capability requires either independent machine measurement of the power (if possible), or a first-principles thermomechanical model based on constitutive data. Note that many models in this field claim to be physically based, but actually calibrate parameters such as friction coefficient as a function of time, which comes to the same thing as calibrating the power directly.

In this work, the net power input $q(t)$ was adjusted empirically with a piece-wise linear variation, in steps of order of 0.05-0.1 sec. Each point value was adjusted in turn until the model matched the measured temperature for the center thermocouple at that time. This only works when the temperature is measured at (or very close to) the heat input, since there is then no time-lag between heat input and temperature response. A $q(t)$ curve was calibrated for each material combination, using the weld of longest duration in each case. This single fitted curve may then be applied for welds of shorter durations, provided all other process conditions are unchanged, simply by truncating the heat input at the appropriate weld time. The resulting net heat generation rate histories are shown in Fig. 5. These show heating patterns that are consistent with an initial ramp-up due to growth of the contact area under frictional sliding, followed by a steady decay of the heat input rate due to progressive material softening. A similar form of power input was inferred in modeling of FSSW in the same materials (Ref 41). Note that the Al-steel weld has a lower heating rate, since deformation is restricted to only one of the sheets. Furthermore, the fall in power input relative to the peak is much greater in the Mg-Al weld, which is consistent with the experimental observation that localized eutectic melting occurred at the interface in welds longer than $0.8 \mathrm{sec}$ (Ref 39).

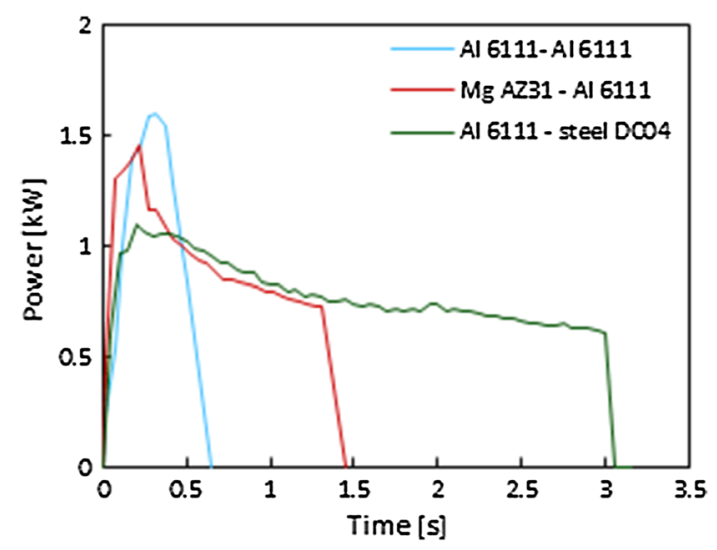

Fig. 5 Heat generation rates with time $q(t)$, inferred from fitting the model to temperature data at the weld center, for each of the material combinations
The longest duration weld available for joining Al 6111 to itself was for a welding time of $0.5 \mathrm{sec}$ (as shown in Fig. 5). For longer welds, sheet thinning was excessive, while for weld times shorter than $0.5 \mathrm{sec}$, it was difficult to obtain meaningful thermocouple data. The measured and predicted thermal histories for the central thermocouple in the $0.5 \mathrm{sec}$ weld are shown in Fig. 6. This indicates how closely the temperature is followed in the rising part of the curve, by calibrating $q(t)$ as far as the temperature peak. For the cooling stage (with $q=0$ ), there is a small discrepancy, but this validates the use of the simple thermal boundary conditions between the workpiece and the sonotrodes and surrounding air.

\subsection{Model Validation}

The predictive capability of the thermal model was tested by comparing with the thermocouple data for the dissimilar welds. Figure 7 shows the data and predictions for Mg AZ31-Al 6111 welds, for thermocouples at the weld center, and in the tool $(0.5 \mathrm{~mm}$ from the tip). The power input $q(t)$ in Fig. 5 was calibrated to the center thermocouple in the $1.3 \mathrm{sec}$ weld, which shows a close fit as far as the temperature peak (Fig. 7a). For shorter duration welds, the predicted temperature rise follows the same curve to the peak, and this is reproduced well in the experimental data at the center. The cooling curve is predicted well in all cases, with the exception of the longest weld, where the cooling rate is overpredicted. For the thermocouples in the tool (Fig. 7b), the agreement is good for all welds, throughout the heating and cooling histories. The model discrepancy is within the experimental reproducibility in the rising part of the different curves, which should (in principle) overlap. The data again confirm that the thermal boundary conditions to the tool and the calibrated power input are reasonable. Temperature histories measured at the weld edges showed too much scatter to provide a meaningful test of the model. The raw data did not overlap during the rising part of each curve, as would be expected. This may reflect a lack of reproducibility in locating the thermocouples at the same distance from the tool.

Figure 8 shows the data and predictions for Al 6111-DC04 steel welds, for both the center and edge thermocouple locations. Here the power input $q(t)$ in Fig. 5 was calibrated to the center thermocouple in the $3 \mathrm{~s}$ weld. As in the $\mathrm{Mg}-\mathrm{Al}$ case, the predicted temperature rise for the center thermocouple (Fig. 8a) follows the same curve to the peak, and this is reproduced reasonably well in the experiments, though there is

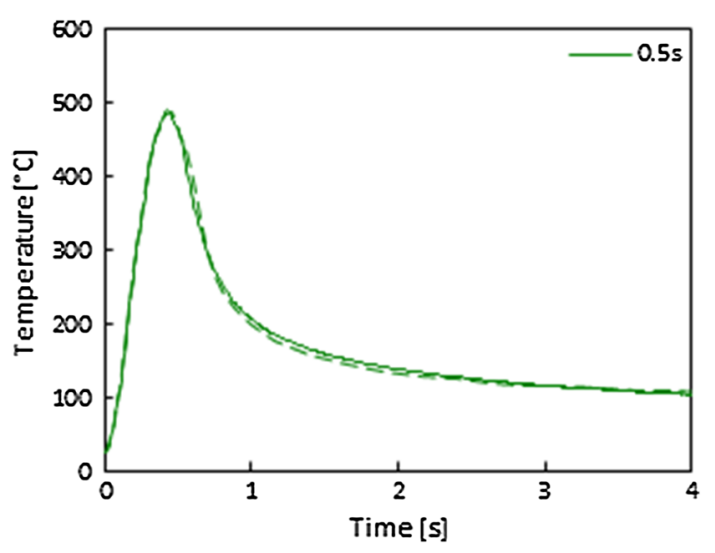

Fig. 6 Experimental temperature (solid line) and calibrated model prediction (dashed line) for a $0.5 \mathrm{~s} \mathrm{Al} 6111-\mathrm{Al} 6111$ weld 

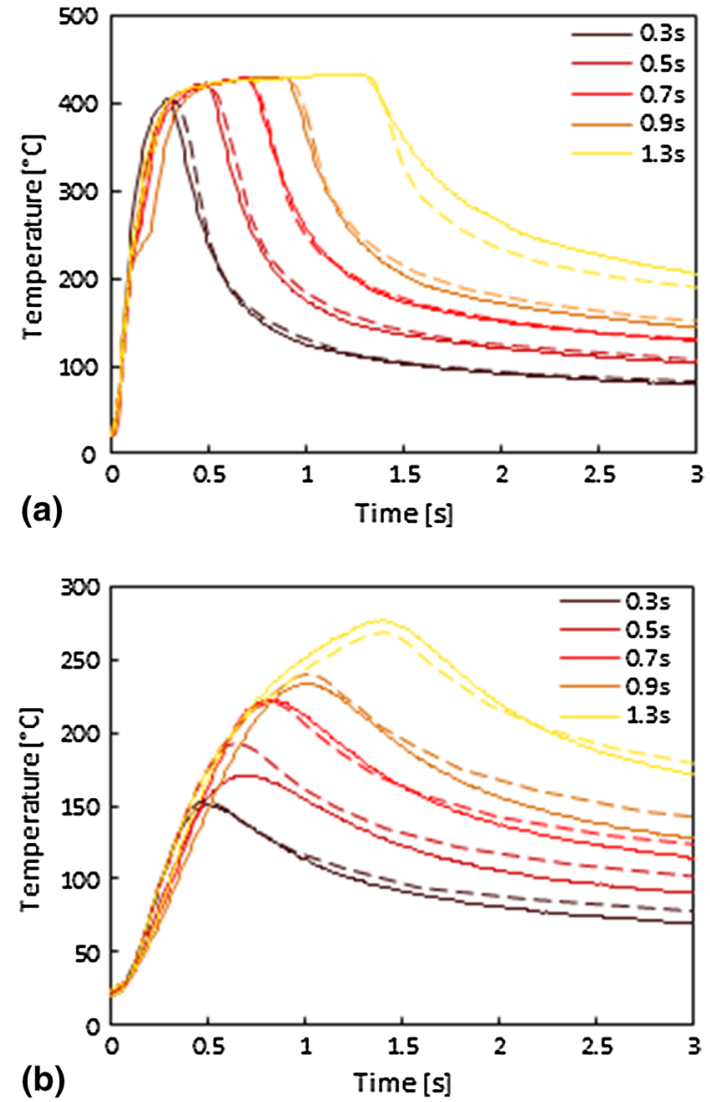

Fig. 7 Experimental temperatures (solid line) and model prediction (dashed line) for Mg AZ31-Al 6111 welds, for various weld times: (a) at the center of the interface, (b) in the tool

more scatter in this case. The cooling part of the curves is all captured to an accuracy within the experimental uncertainty. For the edge thermocouples, the temperature history is consistently under-predicted by up to $50{ }^{\circ} \mathrm{C}$. There is clearly greater uncertainty in these experimental data, as indicated by the lack of consistency in the rising part of the curves (which should overlap). As in the Mg-Al welds, this is most likely due to inaccurate positioning of the thermocouples - because of the large temperature gradient around that location, small positioning inaccuracy has a large effect on temperature readings. But the temperature at the edge will also be more sensitive to the spatial variation of the heat input over the weld area, so the assumption of a uniform distribution may also contribute to the discrepancy. This can only be addressed through a fully coupled thermomechanical model - given the small area of the weld, it is not feasible to embed more thermocouples without disrupting the welding process itself.

Figure 9 shows a comparison between the net energy input to the model and the nominal machine energy (that is, nominal power $\times$ weld time). For Al-Al and Al-steel welds, the total predicted energy input corresponds well with the nominal machine energy. It is not, however, possible to simply assume that the machine energy is correct, and to apply this for other welding conditions directly in the model, since we also need to know the time variation in the power, $q(t)$. Different power curves can of course deliver the same net energy. For Mg-Al, there is an increasing discrepancy with weld time. It is suggested that this reflects the incipient eutectic melting at the interface, observed experimentally in a $1.3 \mathrm{~s}$ weld. As melting
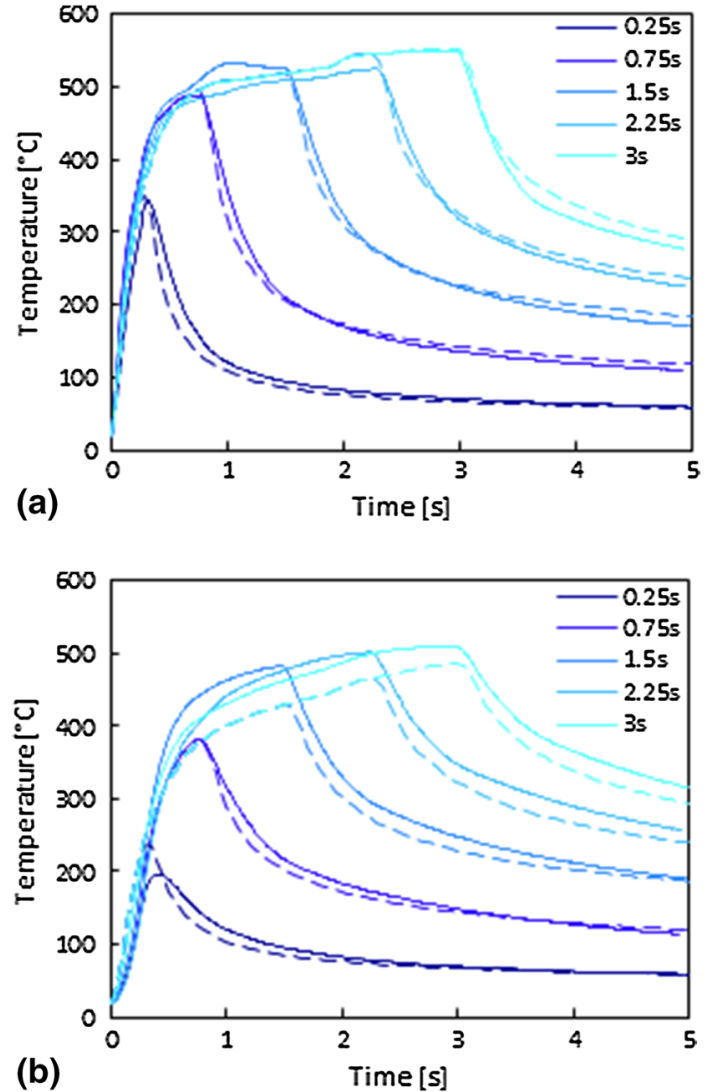

Fig. 8 Experimental temperatures (solid line) and model prediction (dashed line) for Al 6111-DC04 steel welds, for various weld times: (a) at the center of the interface; (b) at the weld edge

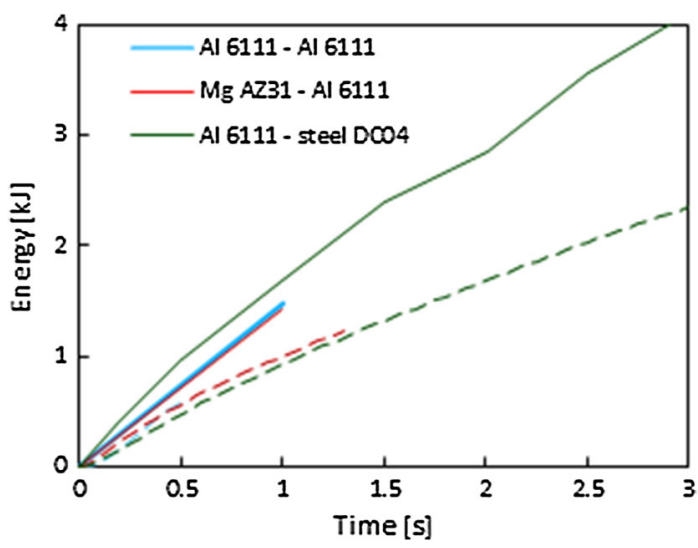

Fig. 9 Nominal machine energy input (solid line) and model prediction (dashed line) for all three material combinations welds

is approached, there will be a steep decline in flow stress and consequent heat generation in the workpiece.

A comparison of the temperature distributions at the weld plane of symmetry, for all three investigated material combinations, is presented in Fig. 10. Thermal maps are plotted on the same temperature scales at 0.5 and $1.3 \mathrm{sec}$, which are the maximum welding times for $\mathrm{Al}$ 6111-Al 6111 and $\mathrm{Mg}$ AZ31-Al 6111 welds, respectively. Note that the temperature fields are symmetrical about the interface in Al-Al (Fig. 10e), whereas in dissimilar Mg-Al and Al-steel welds, the difference in thermal 


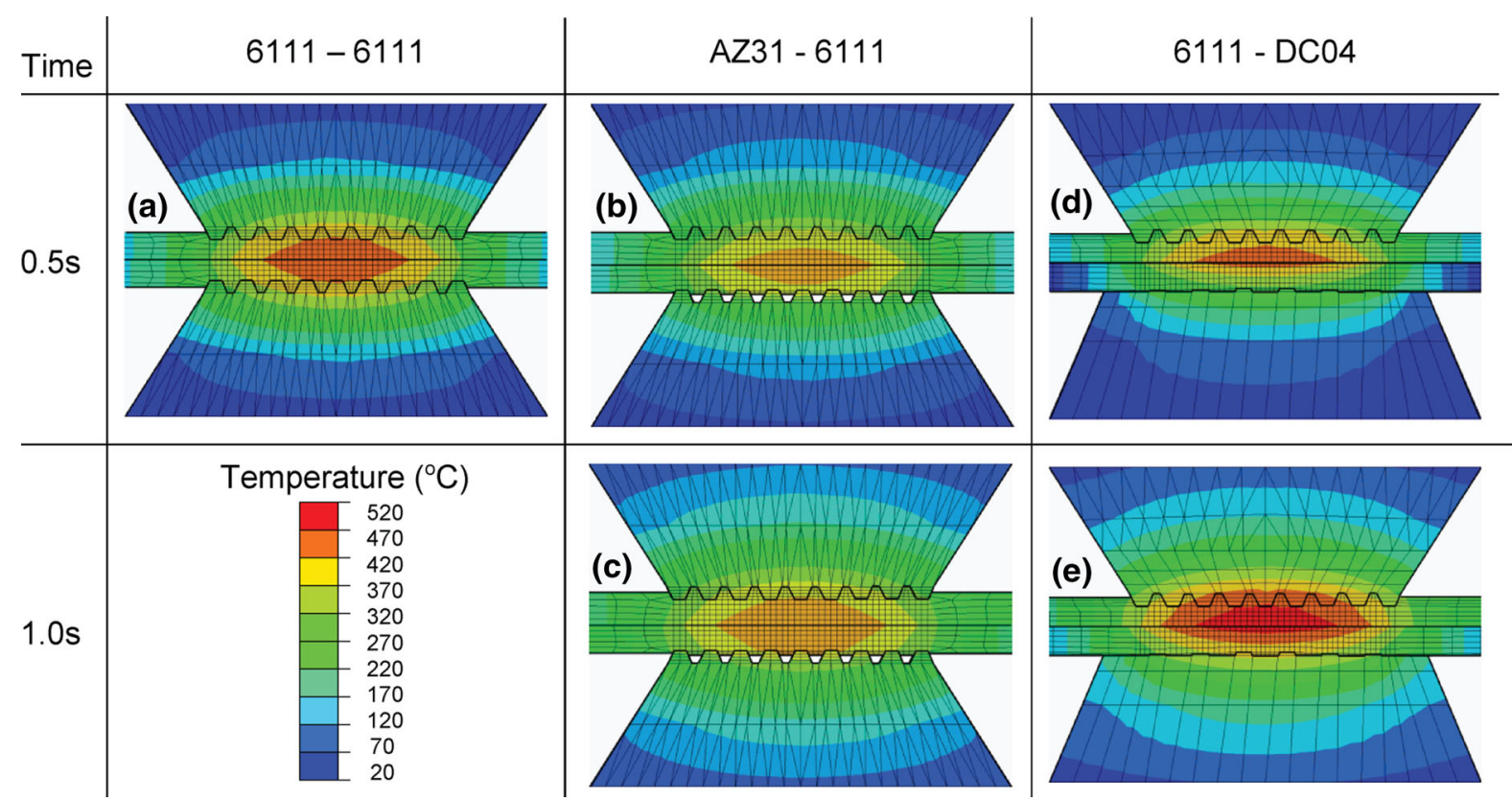

Fig. 10 Predicted temperature distributions after 0.5 and $1.0 \mathrm{~s}$ at the weld plane of symmetry for: (a) Al 6111-Al 6111; (b, c) Mg AZ31-Al 6111; and (d, e) Al6111-DC04 steel

properties leads to an asymmetric temperature field. The lower temperatures observed in $\mathrm{Mg}$-Al welding are consistent with the lower efficiency of energy transfer to the workpiece (Fig. 5).

\subsection{Microstructural Model}

Studies at Manchester University have characterized the formation of intermetallic phases at the interface in $\mathrm{Mg}-\mathrm{Al}$ USW. As these phases are generally brittle, they play an important role in determining the strength of dissimilar welds between $\mathrm{Mg}$ and $\mathrm{Al}$ alloys. An isothermal model has been developed to predict the nucleation and growth of the intermetallics in $\mathrm{Mg}-\mathrm{Al}$ welds (for full details, see Ref 23, 33, and 34). In its simplest form, this model can now be combined with the FE thermal model, to predict the thickness of the intermetallic at the interface after a thermal cycle.

The intermetallic growth model captures the full evolution of the layer from the initial nucleation to the final thickening stage. The model is based on a numerical iteration process, dividing the total welding time into a large number of small time steps with duration $<0.001 \mathrm{sec}$. The rate of microbond formation is predicted using a model initially developed for similar alloy welding (Ref 47). Once microbonds form, diffusion across them is tracked by numerically solving the diffusion equation. Island nucleation is triggered when sufficient enrichment of solute across the interface occurs to enable a critical sized $\mathrm{Al}_{12} \mathrm{Mg}_{17}$ nucleus to form. Spreading of the intermetallic islands then occurs mainly by lateral growth into the solute-enriched matrix close to the interface. During this stage, diffusion across the interface, and the interface-controlled spreading of the intermetallic layer parallel to the interface, occur simultaneously.

As the islands become larger they impinge on one another, and their lateral growth decays to zero. This is predicted in the model using the standard Avrami method for treating 'hard impingement'. When the islands have merged, further thicken- ing of the intermetallic layer is only possible by diffusion through the layer. This thickening rate is predicted using a standard diffusion model for reactive interdiffusion (Ref 48). When the $\mathrm{Al}_{12} \mathrm{Mg}_{17}$ layer reaches a critical thickness, it becomes kinetically favorable for the $\mathrm{Al}_{3} \mathrm{Mg}_{2}$ phase to form. The coupled growth of both phases is then tracked using the reactive interdiffusion model (Ref 48).

This microstructural model has been validated previously by comparing its predictions against experimental measurements of intermetallic layer thickness for both welds, and for longterm diffusion couple experiments. Further details of the model and its validation are given elsewhere (Ref 34).

\section{Prediction of Intermetallic Growth at Interface in Al-Mg Welds}

\subsection{Prediction of Intermetallic Thickness}

First the intermetallic thickness at the center of the interface was predicted for different weld times, using the thermal histories from Fig. 7a, giving the results in Fig. 11. The agreement is good, and (as expected) compares with the outcome, when the individual thermocouple histories were used as input. The sensitivity to temperature is demonstrated in the figure, by running the coupled models with the temperature rise throughout the cycle magnified by a factor of 1.1 (corresponding to $10 \%$ uncertainty in the power input). As discussed by Robson et al. (Ref 34), the calibration of the kinetic constants in the model is difficult, with strong evidence that the diffusion is significantly accelerated by the superimposed high strain-rate deformation. Furthermore, the model is one-dimensional and is idealized to fit the growth of a uniform layer, which would typically require much more prolonged heat treatment than weld cycles operating for under $1 \mathrm{sec}$. It is clear from the experiments that on this timescale, the intermetallic thickness is 


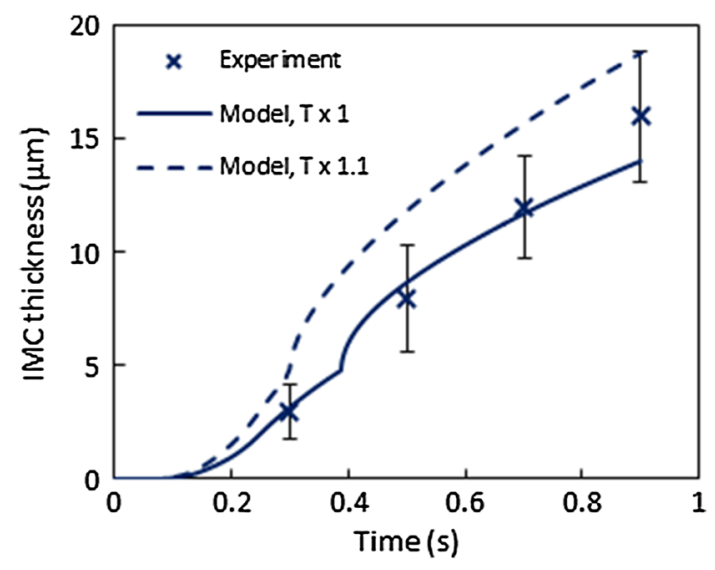

Fig. 11 Data for experimentally measured thickness of the intermetallic layers at the weld interface in four Mg AZ31-Al 6111 welds. The curves show the predicted thickness using the calibrated thermal model (solid line), and with the temperature cycle magnified by a factor of 1.1 (dashed line)

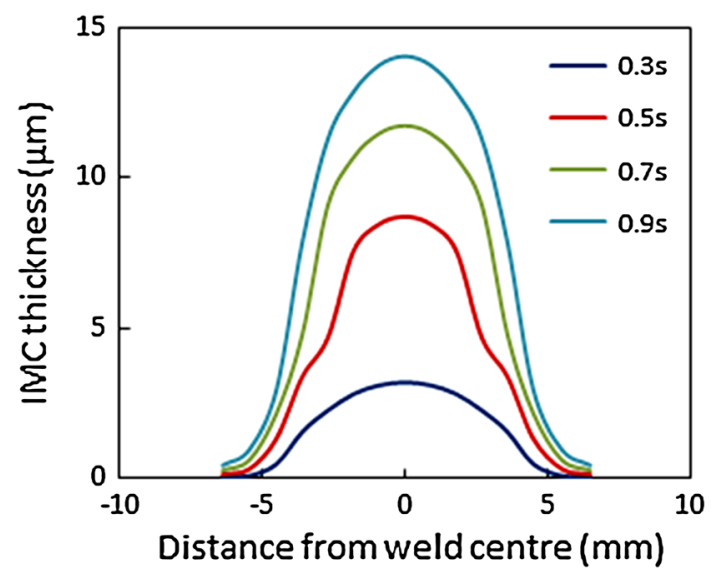

Fig. 12 Predicted variation in thickness of the intermetallic layer with position across the weld interface in Mg AZ31-Al 6111 welds, for four weld times

non-uniform, as isolated nuclei grow and impinge-this accounts for the error bars in Fig. 11. In spite of the uncertainty, the coupled models were used to predict the expected distribution of intermetallic thickness across the weld interface. Figure 12 shows these predictions along the weld center-line in the direction of the longer axis of the rectangular weld tool, for the same welding conditions as Fig. 11. The thickness is predicted to fall off rapidly toward the weld edges, due to the strong temperature dependence of the kinetics of intermetallic growth. Experimental validation of these predictions would be time consuming, but the predicted extent of the intermetallic layer may nonetheless assist in interpretation of the resulting weld failures.

At best, therefore, the microstructural model is semiempirical, and its application here is only intended as a proof of concept, illustrating the coupling of FE-predicted thermal cycles with an isothermal microstructural model. The methodology is equally applicable to other welding processes, such as FSSW. In practice it may be best suited to slower processes for joining dissimilar alloys, such as rotary friction welding, for which the weld thermal cycles last for many seconds.

\section{Conclusions}

A 3D finite element thermal model has been developed for ultrasonic welding. The power input as a function of time was inferred via thermocouple data, and is consistent with a transition from frictional stick-slip to full seizure and plastic deformation, with progressive material softening. The model successfully predicted temperature histories for three material combinations: Al 6111-Al 6111, Mg AZ31-Al 6111, and Al 6111-DC04 steel. It was sufficiently accurate to assume that the heat input was concentrated at the weld interface, with a uniform spatial distribution, and to assume near-perfect thermal contact between the tools and workpiece, and between the workpieces in the weld region.

For the $\mathrm{Mg}-\mathrm{Al}$ alloy welds, the temperature histories were coupled with a microstructural model for the growth of an intermetallic compound layer at the joint interface. The accuracy of the model was reasonable, given the short weld timescales, the simplifications in the microstructural model, and the uncertainty in calibration of kinetic constants when diffusion is superimposed on intense plastic deformation.

To develop further insight into the metal deformation and heat generation in dissimilar alloy ultrasonic welding, a full thermomechanical FE model is required, coupling the temperature field to the constitutive plastic responses of the materials. A computationally efficient process for this analysis, using the thermal model presented here, will be reported in a subsequent paper.

\section{Acknowledgments}

The work described in this paper was funded by the UK Engineering and Physical Sciences Research Council (EPSRC) via the following grants: Friction Joining - Low Energy Manufacturing for Hybrid Structures in Fuel Efficient Transport Applications (EP/ G022402/1 and EP/G022674/1), and LATEST 2: Light Alloys Towards Environmentally Sustainable Transport, 2nd Generation Solutions for Advanced Metallic Systems (EP/H020047/1). Mr. Jedrasiak is also supported by EPSRC through the University of Cambridge Doctoral Training Account, with additional CASE award funding provided by TWI, Granta Park, Cambridge, UK.

\section{References}

1. L. Quintino, P. Vilaca, R. Rodrigues, and L. Bordalo, Laser Beam Welding of Automobile Hinges, Weld. J., 2001, 80(11), p 261S-267S

2. S.J. Lee, S. Katayama, Y. Kawahito, K. Kinoshita, and J.D. Kim, Weldability and Keyhole Behavior of Zn-Coated Steel in Remote Welding Using Disk Laser with Scanner Head, J. Laser Appl., 2013, 25(3), p 032008

3. K.R. Chan and N.S. Scotchmer, Quality and Electrode Life Improvements to Automotive Resistance Welding of Aluminum Sheet, Sheet Metal Welding Conference XIII, (Detroit), 2008

4. J. Bruckner, Joining Steel to Aluminum in Heat-Intensive Applications, 28.08.2003 [Online], http://www.thefabricator.com/article/metalsmaterials/ considering-thermal-processes-for-dissimilar-metals. [Accessed 17.09.2012]

5. P. Hornet, Fracture of Weld Including Mismatch Effect, 16 International Conference on Structural Mechanics in Reactor Technology, (Washington, DC), 2001

6. S. Bozzi, A.L. Helbert-Etter, T. Baudin, B. Criqui, and J.G. Kerbiguet, Intermetallic Compounds in Al 6016/IF-Steel Friction Stir Spot Welds, Mater. Sci. Eng. A, 2010, 527(16-17), p 4505-4509

7. W. Lee, K. Bang, and S. Jung, Effects of Intermetallic Compound on the Electrical and Mechanical Properties of Friction Welded $\mathrm{Cu} / \mathrm{Al}$ 
Bimetallic Joints During Annealing, J. Alloys Compd., 2005, 390(1-2), p 212-219

8. G. Çam and M. Koçak, Joining of Advanced Materials, Encyclopedia of Life Support Systems, Area 6: Materials science and engineering, Topic 6.36.4: Material processing and manufacturing technologie, (Oxford) Eolss

9. T. Stotler, What You Need to Know About Friction Welding Processes, EWI, 2012, 24, p 7

10. A.M.M. García, BLISK Fabrication by Linear Friction Welding, Advances in Gas Turbine Technology, InTech, Rijeka, 2011, p 411-434

11. Ultrasonic Welding [Online]. http://www.isf.rwth-aachen.de/index. php?id $=186 \& \mathrm{~L}=1$. [Accessed 08.11.2013]

12. M. Frost, Ultrasonics Gets To Grips with Metal Welding (Telesonic UK Limited, Poole)

13. I. Chang and J. Frisch, On Optimization of Some Parameters in Ultrasonic Metal Welding, Weld. J., 1974, 53, p S24-S35

14. R. Jahn, R. Cooper, and D. Wilkosz, The Effect of Anvil Geometry and Welding Energy on Microstructures in Ultrasonic Spot Welds of AA6111-T4, Metall. Mater. Trans. A, 2007, 38, p 570-583

15. A. Weber, The Economics of Ultrasonics, Assembly Magazine, 1 August 2003

16. E.P. DeGarmol, J.T. Black, and R.A. Kohser, Ultrasonic Welding, DeGarmo's Materials and Processes in Manufacturing, 11th ed., Wiley, Etobicoke, ON, 2011, p 904-906

17. F. Balle, G. Wagner, and D. Eifler, Characterization of the Ultrasonic Welding Process through High-resolution Laser-Doppler Vibrometry, Opt. Meas. Solut., 2009, 1, p 2-4

18. D. Bakavos and P.B. Prangnell, Mechanisms of Joint and Microstructure Formation in High Power Ultrasonic Spot Welding 6111 Aluminium Automotive Sheet, Mater. Sci. Eng. A, 2010, 527, p 6320-6334

19. M. Annoni, F. Moroni, and V. Mussi, Performance Variability of Aluminium Hybrid Lap-Joints Obtained by Means of Adhesives and Ultrasonic Welding, Int. J. Mater. Form., 2010, 3, p 1051-1054

20. Z. Zhu, K.Y. Lee, and X. Wang, Ultrasonic Welding of Dissimilar Metals, AA6061 and Ti6A14V, Int. J. Adv. Manuf., 2012, 59, p 569574

21. M. Annoni and M. Carboni, Ultrasonic Metal Welding of AA 6022-T4 Lap Joints: Part I-Technological Characterisation and Static Mechanical Behaviour, Sci. Technol. Weld. Join., 2011, 16(2), p 107-115

22. S. Elangovan, S. Semeer, and K. Prakasan, Temperature and Stress Distribution in Ultrasonic Metal Welding-An FEA-Based Study, $J$. Mater. Process. Technol., 2009, 209, p 1143-2250

23. A. Panteli, Y.C. Chen, D. Strong, X.Y. Zhang, and P.B. Prangnell, Optimization of Aluminium-to-Magnesium Ultrasonic Spot Welding, J. Miner. Met. Mater. Soc., 2012, 64(3), p 414-420

24. V.K. Patel, S.D. Bhole, and D.L. Chen, Formation of Zinc Interlayer Texture During Dissimilar Ultrasonic Spot Welding of Magnesium and High Strength Low Alloy Steel, Mater. Des., 2013, 45, p 236-240

25. E. Sooriyamoorthy, S. Ponnayya, J. Henry, and P. Kalakkath, Experimental Studies on Optimization of Process Parameters and Finite Element Analysis of Temperature and Stress Distribution on Joining of $\mathrm{Al}-\mathrm{Al}$ and $\mathrm{Al}-\mathrm{Al}_{2} \mathrm{O}_{3}$ Using Ultrasonic Welding, Int. J. Adv. Manuf. Technol., 2011, 55, p 631-640

26. A. Siddiq and E. Ghassemieh, Thermomechanical Analyses of Ultrasonic Welding Process Using Thermal and Acoustic Softening Effects, Mech. Mater, 2008, 40, p 982-1000

27. A. Siddiq and E. Ghassemieh, Theoretical and FE Analysis of Ultrasonic Welding of Aluminum Alloy 3003, J. Manuf. Sci. Eng., 2009, 131, p 1-11

28. W. Kim, A. Argento, A. Grima, D. Scholl, and S. Ward, Thermomechanical analysis of frictional heating in ultrasonic spot welding of aluminium plates, Proc. Inst. Mech. Eng. Part B, 2011, 225(B7), p 1093-1103

29. C. Zhang and L. Li, A Friction-Based Finite Element Analysis of Ultrasonic Consolidation, Weld. J., 2008, 87, p 187-194

30. C. Zhang and L. Li, Effect of Substrate Dimensions on Dynamics of Ultrasonic Consolidation, Ultrasonics, 2010, 50, p 811-823

31. C. Zhang and L.J. Li, A Coupled Thermal-Mechanical Analysis of Ultrasonic Bonding Mechanism, Metall. Mater. Trans. B, 2009, 40(2), p 196-207

32. A. Reilly, H.R. Shercliff, G.J. McShane, Y. Chen, and P. Prangnell, Novel Approaches to Modelling Metal Flow in Friction Stir Spot Welding, 10th International Seminar Numerical Analysis of Weldability, (Graz), 2012

33. A. Panteli, J.D. Robson, I. Brough, and P.B. Prangnell, The Effect of High Strain Rate Deformation on Intermetallic Reaction During Ultrasonic Welding Aluminium to Magnesium, Mater. Sci. Eng. A, 2012, 556, p 31-42

34. J. Robson, A. Panteli, and P.B. Prangnell, Modelling Intermetallic Phase Formation in Dissimilar Metal Ultrasonic Welding of Aluminium and Magnesium Alloys, Sci. Technol. Weld. Join., 2012, 17(6), p 447-453

35. F. Haddadi, Joint Performance and Interface Reactions in Dissimilar Aluminium to Steel Ultrasonic Spot Welding, PhD thesis, The School of Materials in The University of Manchester, Manchester, 2012

36. Y.-C. Chen, D. Bakavos, A. Gholinia, and P.B. Prangnell, HAZ Development and Accelerated Post-weld Natural Ageing in Ultrasonic Spot Welding Aluminium 6111-T4 Automotive Sheet, Acta Mater, 2012, 60(6-7), p 2816-2828

37. Y.-C. Chen, D. Bakavos, A. Gholinia, and P.B. Prangnell, Accelerated Post-weld Natural Ageing in Ultrasonic Welding Aluminium 6111-T4 Automotive Sheet, 13th International Conference on Aluminum Alloys: ICAA 13, (Pittsburgh, PA), 2012

38. P. Prangnell, F. Haddadi, and Y.C. Chen, Ultrasonic Spot Welding of Aluminium to Steel for Automotive Applications-Microstructure and Optimisation, Mater. Sci. Technol., 2011, 27(3), p 617-624

39. A. Panteli, Friction Joining of Aluminium-to-Magnesium for Lightweight Automotive Applications, $\mathrm{PhD}$ thesis, Manchester University School of Materials, Manchester, 2012

40. Implicit Versus Explicit Dynamics, Abaqus Analysis User's Manual, (Providence) Dassault Systèmes, 2011, p 6.3.1-1-2

41. P. Jedrasiak, A. Reilly, H.R. Shercliff, G.J. McShane, Y.C. Chen, and P. Prangnell, Thermal modelling of Al-Al and Al-steel Friction Sitr Spot Welding, 10th International Seminar Numerical Analysis of Weldability, (Graz), 2012

42. S.K. Khanna, X. Long, W.D. Porter, H. Wang, C.K. Liu, M. Radovic, and E. Lara-Curzio, Residual Stresses in Spot Welded New Generation Aluminium Alloys Part A-Thermophysical and Thermomechanical Properties of 6111 and 5754 Aluminium Alloys, Sci. Technol. Weld. Join., 2005, 10(1), p 82-87

43. S. Lee, H.J. Ham, S.Y. Kwon, S.W. Kim, and C.M. Suh, Thermal Conductivity of Magnesium Alloys in the Temperature Range from $-125{ }^{\circ} \mathrm{C}$ to $400{ }^{\circ} \mathrm{C}$, Int. J. Thermophys., 2013, 34, p 2343-2350

44. K.W. Tupholme, Steels, 2.2.2011 [Online]. http://www.thermopedia. com/content/1152/. [Accessed 23.05.2014]

45. E. Alam, S. Han, Q.B. Nguyen, A.M.S. Hamouda, and M. Gupta, Development of New Magnesium Based Alloys and Their Nanocomposites, J. Alloys Compd., 2011, 509(34), p 8522-8529

46. G. Elert, The Physics Factbook: Density of Steel [Online]. http://hypertextbook.com/facts/2004/KarenSutherland.shtml. [Accessed 23.05.2014]

47. J.L. Harthoorn, Ultrasonic Metal Welding, PhD thesis, Eindhoven University of Technology, Eindhoven, 1978

48. J. Philibert, Materials Science Forum, 1994, 155-156, p 15-30 